\title{
Absorptive capacity in low-tech industry: Case Study of Indonesian Manufacturing Companies
}

\author{
Lutfah Ariana $^{1}$, Indri Juwita Asmara ${ }^{2}$ \\ ${ }^{1,2}$ Research Center for Science and Technology Development, Indonesian Institute of Sciences
}

\begin{abstract}
Innovation has widely recognized as an important factor for driving competitiveness of many firms. In order to generate innovative performances, firms need to improve their capabilities in absorbing knowledge and technology from external sources, which is so called absorptive capacity. This paper will analyze what kind of sources of innovation in manufacturing sectors especially for low tech industries. Focusing on innovation activities, this paper aims to identify what kind of determinants in influencing the difference of absorptive capacity in low tech industries. The source of data is derived from Innovation Survey 2011 held by Center for Science and Technology Development Studies. The survey conducted for 1360 firms in manufacturing sector, in which most of the distribution is mainly consisted of low technology sectors. Instead of quantitative approach, the result is also supported by in depth interview from selected firms observed in 2013. This paper addresses multiple case studies as the qualitative approach, including firms in food and beverages, and jewelry art and design. According to the results, most of low tech companies searched their external sources of knowledge from their market, and customers were the main driver for their innovation output. In respond to this situation, this paper proposes an idea of open innovation for enhancing industrial competitiveness. As policy insights, the sources of competitive advantage in an open innovation setting will encourage the firm to the internal organizational processes that allow a firm to recognize, assimilate and exploit knowledge.
\end{abstract}

Keywords: absorptive capacity, source of innovation, low tech, manufacturing, companies

\section{Introduction}

To support the company's sustainability, competitiveness becomes an important key in its success. A company that has a competitive advantage will be able to use existing resources efficiently and effectively. One of the driving forces of competitive advantage that is believed in today's business world is innovation. The company's ability to innovate is highly dependent on good sources of information about markets, technologies and other strategic resources that can be an advantage in competition.

Creating innovation is an important factor for increasing productivity and competitive advantage in the manufacturing industry. How innovation activities revealed in manufacturing industry can be seen through innovation survey 2011 conducted by Pappiptek LIPI. This survey provided an overview of the application of science and technology to produce goods and services benefited for the fulfillment of societal needs and to generate competitive advantage for domestic and export markets. This survey was categorized in term of technology intensity, whereas: Low Technology, MediumLow Technology, Medium-High Technology, and High Technology. As can be seen in Figure 1, innovations to create products from both high-tech industries and low- technology industries have almost the same level ranging from $60 \%$ to $67 \%$.

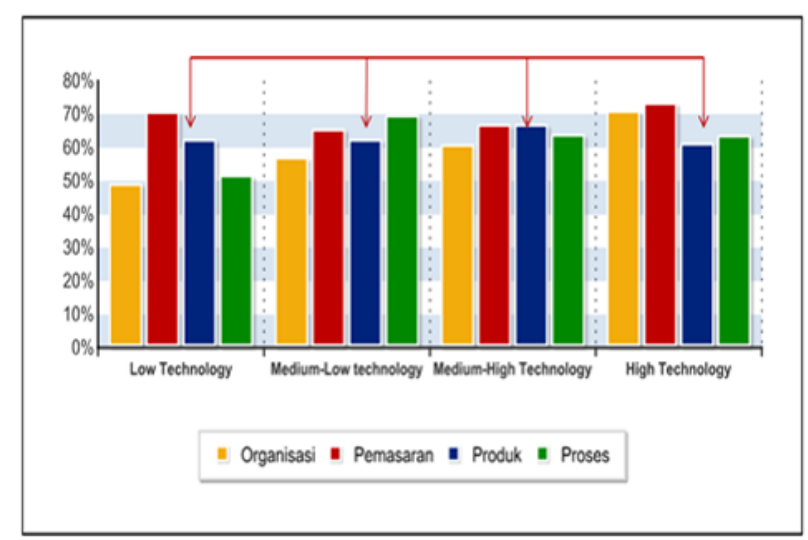

Figure 1. Product innovation in manufacturing sectors based on intensity of technology

Based on data obtained from the same survey, low technology manufacturing industries are also able to absorb technology to create new products in the market higher than firms in medium-tech and high technology intensity areas. This result is shown in the following Figure 2. 


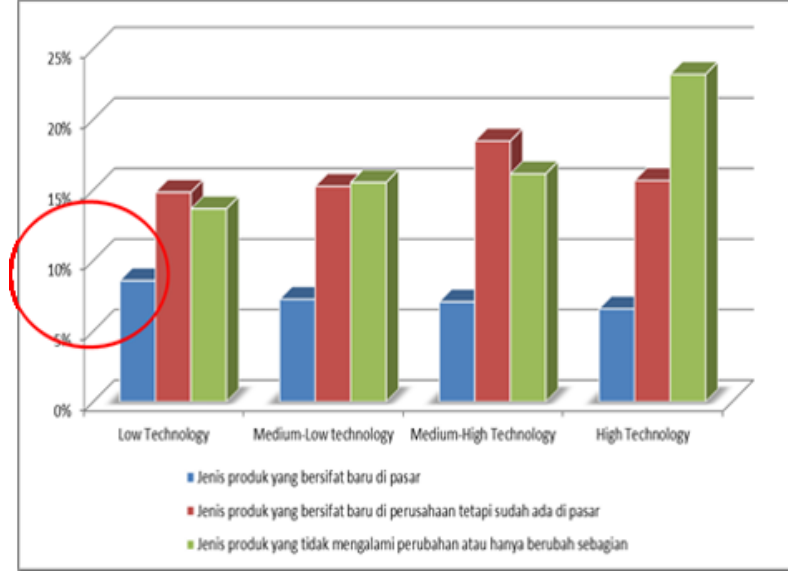

Figure 2. Technology absorption in manufacturing sectors based on technology intensity

This result was interesting, because the low-tech manufacturing industry contributed greatly to the economic development in Indonesia, especially the food and beverage industry. The food and beverage industry was the largest populations compared to other industries, as shown in the following Figure.

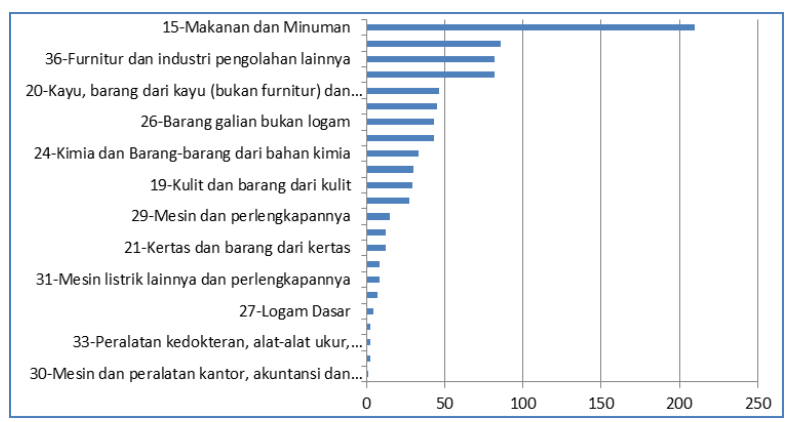

Source : Innovation Survey Pappiptek (2011)

Figure 3. Distribution of the number in manufacturing companies by ISIC

According to the survey result, in Indonesia, nearly $80 \%$ of manufacturing industry was dominated by food and beverage sectors. This industry is also including the non-oil and gas industry with the most contribution to GDP of $73.65 \%$ in 2011 by total employment amounted for 715,648 in 2010 (BPS). The value added increased from $\mathrm{Rp} 34,733$ billion in 2001 to reach $\mathrm{Rp}$ 166,012 billion in 2010 . Through this data it can be said that low-tech manufacturing industries such as food and beverage industry have played an important role in the positive economic growth rate. Creation of innovations with low technology intensity environments is generated through the process of information absorption into useful knowledge for the company. Therefore, absorptive capacity in low technology manufacturing industry becomes interesting to be studied.

Some previous studies widely recognized that nontechnological forms of innovation have also contributed in upgrading a firm's performance (Piva and Vivarelli, 2002; OECD, 2005 and Arundel et al., 2008). In other words, innovation performance in a firm can be identified as an activity occurring in low and medium tech sectors (e.g. Kirner et al., 2009). Jensen et al. (2007) considered two different modes of innovation, "Science, Technology and Innovation" and "Doing, Using, Interacting" (DUI). The interesting mode of Doing, Using and Interacting is mostly occured in low tech sectors and it relied on processes and experience-based know how. This kind of learning may not require formal $R \& D$ programmes, but incremental problem solving and experimentation are significantly improved the production performances. However, there is still little evidence on innovation activities in low tech sectors.

In fact, the contribution of low and medium tech sectors is more than $90 \%$ to the economy of the $\mathrm{EU}$ (see Robertson et al., 2003), while a large number of industrialized OECD countries has a significant contribution to employement for more than $60 \%$. In addition, the importance of low-medium tech sectors in a firm is very crucial since this kind of sectors have innovation capability to create product development (Hirsch-Kreinsen, 2008). Therefore, this paper attempts to understand the innovation activities of low-medium tech sectors and its relation to absorptive capacity to identify the key determinants for pursuing sustainability of their competitiveness in long term period.

\section{Absorptive Capacity and Innovation Perfor- mance}

Absorptive capacity is a functional concept, and in practice it is based on an interdependent foundation of capabilities, structures, routines and policies, and is largely situation-specific. For this reason it is not possible to develop a set of reliable standard indicators of absorptive capacity.

Absorptive capacity is the company's ability to absorb knowledge from various sources of information used to generate innovation within the company. The absorptive capacity within a company depends heavily on the company's ability to receive information as a source of knowledge. Some literature described the various processes that occur in absorbing knowledge. The concept of absorptive capacity was first introduced by Cohen \&Levinthal (1990) in his book Absorptive capacity: a new perspective on learning and innovation. Cohen \&Levinthal (1990) mentioned "Absorptive capacity, the ability of a firm to recognize the value of new, external information, assimilate it, and apply it to commercial ends is critical to its innovative capabilities." Katz, J. Corbett, A. C. (1995) and Camisón \& Forés (2010) formulated four dimensions: acquisition, assimilation, transformation and exploitation. The result of these four dimensions is an innovative output, as shown in the following figure. 


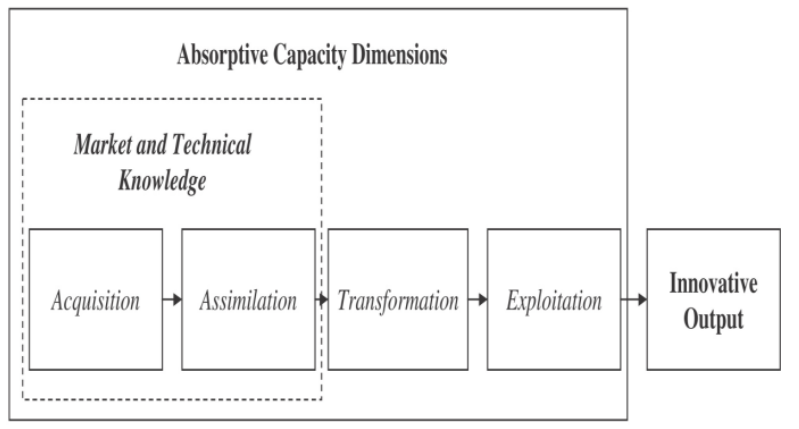

Figure 4. Dimensions of absorptive capacity

According to Lane et al., (2006, p.849) absorptive capacity contributes to increase the speed, frequency and magnitude of an innovation. The improvement of innovation capability is strongly supported by the absorptive capacity that provides an in-depth understanding of the various domains or sources of knowledge in accordance with the core competencies of the company (Van den Bosch et al., 1999). Innovation that focuses on the content of knowledge generated by the company can be in the form of patents and new products.

The absorptive capacity is began by recognizing the value of external information that the company might use, this information is then assimilated into a knowledge then used for commercial purposes. The process of recognize, assimilate and apply is a series of activities that are linear. In addition, Zahra \& George (2006) suggests that there are four dimensions in absorptive capacity: acquisition, assimilation, transformation and exploitation, then they further stated that the four processes are divided into two components: Potential Absorptive Capacity (PACAP) means acceptable and acceptable external knowledge opportunities, and Realized Absorptive Capacity (RACAP) means external knowledge that has effectively been exploited by the company. In their seminal works, it described that there is an interrelated relationship between PACAP and RACAP, both of which are different but interdependent with each other. RACAP is unlikely to be executed without the process of acquiring information and assimilating the information into new knowledge of the company, and vice versa.

Some research emphasizes the role of strategy or action orientation as a key factor in the success of absorptive capacity. This is confirmed by Liao et al (2003) who conducted a survey of several companies, and found that in the process of acquiring new knowledge, the more innovative a company would be the greater the company's commitment to action against existing opportunities. Therefore, the absorptive capacity and innovation capabilities within the company are closely related and interdependent. The absorptive capacity is a dimension of innovation capability, in the process of identifying, assessing, acquiring and integrating external knowledge into competitive advantage is an asset for innovation.
Van den Bosch also considers absorptive capacity as a key contributor to organizational performance outcomes (Van den Bosch, 2003), such as:
- Competitive advantage, financial perfor- mance, in-company knowledge flow and knowledge transfer
- Innovative performance and new product development
- $\quad$ Learning within organizations and interna- tional co-operation
- Establishment of expectations, proactive strategies, strategic renewal, diversifica- tion and adaptation of the organization;

Therefore, it can be described that the increase in absorptive capacity is directly proportional to the improvement of innovation capability within the company. The better the absorptive capacity of a company, the more innovative the company will be.

PACAP consists of the dimensions of acquisition and assimilation, while RACAP consists of transformation and exploitation. Figure 5 shows a general picture of PACAP and RACAP conditions in low technology sectors in Indonesia. The most densely areas are indicated by red. Thus, it can be seen that most of the low technology industries in Indonesia have a higher PACAP index than the RACAP index.

Furthermore, to see the absorptive capacity can also be seen from the efficiency of absorptive capacity. The efficiency of absorptive capacity is the ratio between RACAP and PACAP indexes. The higher the resulting efficiency value, it means the RACAP index is much higher than the company's PACAP index. That is, the company is able to transform all the knowledge absorbed into a concrete form. The efficiency of absorptive capacity has a range of values between $\infty$ and 0 , where value 1 is a state of equilibrium. The value of absorptive capacity efficiency of 1 means the PACAP index is balanced with the RACAP index. In other words, the company can change all the knowledge absorbed into a concrete form with a balanced.

\section{Results and Discussions}

The result of this study found that low technology sector in Indonesia is a typical labor-intensive industry and less intensive in applying technology. Another result showed that most of innovation type in low technology sector is a kind of radical change. The idea of innovation in the low-tech industry is largely determined by market demand, rather than science push. These ideas were derived from various sources of information or knowledge ranging from competitors, suppliers, partners, customers, various media information, expertise to owners of expert knowledge. Figure 5 shows that the red area is below the diagonal line. Thus, the efficiency of absorptive capacity in low technology industry firms is generally relatively low (below 1). That is, the company has been doing the process of assimilation and knowledge acquisition but it is difficult 
to manage the process of transformation and exploitation that is comparable with assimilation and acquisition.

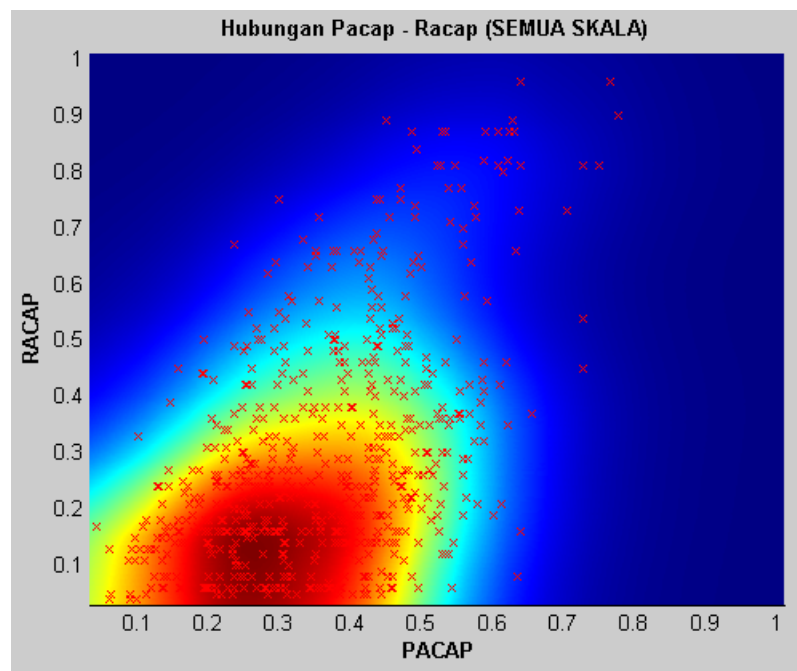

Source : Asmara et. al (2013)

Figure 5. Relationship between PACAP and RACAP in low tech sectors

Based on the regional mapping of the potential of absorptive capacity and the realization of absorptive capacity, it can be described as follows. Low technology sectors in Indonesia tend to be in potentially low absorptive capacity positions and have not achieved high factor efficiency. According to the scale of the business (the amount of labor), the pattern of absorptive capacity indicated the dominance of low-tech mid-scale industry compared to large-scale manufacturing industry.

In this case, large-scale group companies have a more specific pattern, which is closer to the factor efficiency line, meaning that large-scale industries are more efficient at converting the potential absorptive capacity into higher realization or innovative performance than middle-scale enterprise groups.For export activities, the group of exporting companies expressed a pattern of distribution of absorptive capacity that tends toward a factor efficiency line with a relatively high realization rate.In terms of capital ownership (capital status), group companies that conduct joint ventures tend to have a pattern of distribution of absorptive capacity close to the line of factor efficiency and the level of realization of higher absorptive capacity.

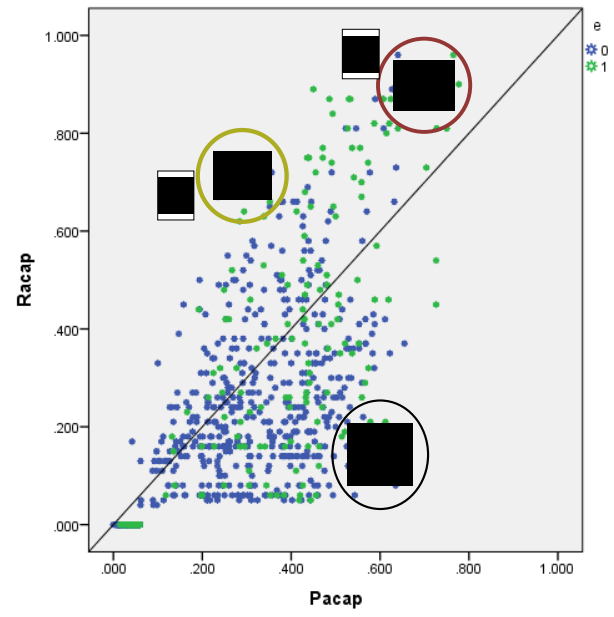

Source : Asmara et. al (2013)

Figure 6. Distribution of companies in low tech sectors by efficiency factor

This study also analyzes the relationship of potential absorptive capacity (PACAP) and its realization (RACAP). Based on Figure 6, the highest efficiency level is Area B, it could be considered as the best case in realizing absorptive capacity. Most of the low technology industry in Indonesia is dominated by industries located in Region $\mathrm{C}$ and Region $\mathrm{D}$ characterized by importing machinery, equipment or software to produce product and process innovation, conduct its own R \& D activities (intramural), the percentage of labor with undergraduate $>5 \%$, the percentage of labor involved in $\mathrm{R} \& \mathrm{D}$ activities $>5 \%$, Joint Venture ownership status, percentage of export value $>50 \%$, average sales value per year $>$ Rp 1 billions.

In order to describe how absorptive capacity in specifically implemented in firm level, this paper investigated two case studies in low tech sectors (region $\mathrm{A}$ and region B), selected from the survey result.

\section{Case study 1: A bottled drinking water compa- ny}

Company A operated since 2003, with main production was mineral water packaged. As food and beverages company, this company has expanded its business to similar products such as tea drink, fruit juice, energy drink, and other canned beverages. One of the recent innovation product was mineral water in gallon package with easy-handle and made from non-poly carbonate, which has been based on eco-friendly technology.

This company has a wide range of production line starting from downstream up to upstream units, including the packaging materials produced as in house/in site. In order to support the technological capability of the company and to control the quality of final products, a set of machinery supports was imported from Germany. In 2013, Company A has developed 11 plants supported by integrated procurement, packaging and final product control sites. For its efforts, this company has 
been awarded an achievement in 2008 for ISO 22000: 2005 for high quality standard and production standard process.

In an effort to generate innovation, the company explored information from various sources, mainly from visiting international exhibitions held every 3 years. These visits were mostly conducted by representatives of the board of directors, as the main decision maker for strategic purposes. By engaging in this expo, the company had opportunities to obtain new information on advance technology products provided by most leading suppliers from various countries, especially manufacturing technology, packaging materials (plastic), and machineries.

In addition to this information, the company also investigated new product ideas by having market survey, benchmarking from product's competitors, examining emerging trends of product development, and tracing information about technology suppliers and new packaging materials by internet supports.

This company searched relevant information and then assimilated the significant knowledge for creating idea for product innovation. In addition, other important information such as how to reduce production cost, the changing trend of bottle-to-bottle product packaging, or information about the trend of change in the bottle net content of $330 \mathrm{ml}$ is now a $295 \mathrm{ml}$ net bottle size. From the various information, representatives from companies usually represented by the director of the company and other teams about 8 people discuss together to find new ideas that will be the future product development plan at the company.

The ideas of product innovation are reviewed and conducted in special research to know the product content in detail and the feasibility of developing the new product as needed. The selection of innovation ideas was discussed in special meetings at the managerial level and further explored to finalize the existing concepts.

Transformation process in the dimension of absorption capacity focuses on integrating information from external sources into the capabilities already owned by the company. In this case, the company has developed special research, for example for developing new packaging of mineral products that has been decided as the potential innovation. When the company has got the idea of innovation for lab scale, they put some efforts to find the appropriate supplier. Information about the supplier itself has been collected from the exhibition, then they will communicate and analyze some feasibilities of purchasing materials. For example, a company needs a robotic packer to manufacture its new packaging material, then the company will contact directly to the supplier for planning the input. If there is unclear and insufficient information regarding product and technology specifications, then the company invites suppliers to explain more about it.

When the new design has been generated, it will be executed by the Operational Division. For laboratory- scale execution, the company will put an investment for a new machine or a new technology. As for mass production, the company firstly developed its ideas and further reviewed the feasibility of production both in terms of cost and the prospect of sustainability of the product in the long run. In this case, the company admitted not buying a new machine, but making its own machine by having consultation with the manufacturer. If needed, a high support in operating production facilities wil be encouraged for improving the capacity of the human resources by distributing trainings and workshops.

The dimension of exploitation in this case is understood as the company's efforts in developing innovation ideas into commercialization activities that generate economic benefits. In addition to good innovations in the form of new products and new packaging, the company also developed co-branded products with other companies. Co-branding products are a product with two brands which are preferred for low-end products and affordable price for consumers. As sharing partners, this company focused on packaging innovation, and the partner has the potential for distribution networks of marketing and wide distribution of products through their outlets. Cooperation of both is quite capable to accelerate the process of commercialization of new products.

To maintain and continue the development of innovation products, the company implemented a Balance Score Card system where innovation performance was evaluated according to its Key Performance Indicator (KPI). The evaluation was done twice a year. While routine evaluation was applied every month for each factory. The achievement of this company is a form of company commitment to expand product distribution network in various regions.

As its commitment to be sustain in domestic market, the company put a high concern for being a cost leadership. For example, it can be seen from the product packaging made with the lowest gramation per cup. Since 2005, this company has produced the lightest cup capacity in Indonesia. In addition, the company also continues to seek new innovations in packaging such as gallons of water refill handled with BPA free raw material. With these breakthroughs, the company tried to meet the demand of consumers at the lowest price level. In addition to product innovation, the company also focuses on economical and environmentally friendly products without neglecting added value to end customers.

\section{Case study 2: Company B and the jewelry products}

At the beginning of its establishment, Company B is a type of home industry producing jewelry since 1958. As a family business, the company expanded her products market through several gold shops run independently. In the late 1990s to 1998 the company began 
building small factories to produce its own jewelry products.

Information as a source of innovation was largely derived from market survey activities, especially those related to jewelry trends based on customer preferences. To meet the diverse demands of the market, the company identified several important aspects, including: demographic factors, motivation of consumption, fashion trends in different periods, geographical factors (consumers in the village and town), and so on. To improve the company's performance, Company B has changed the management that was initially family-based into professional management. In addition, the company also conducted outsourcing human resources e.g experts in the field of art and design to provide new ideas in jewelry and feedback on organizational management. The existence of professionals in the organization of the company has provided learning organization that focused on way of thinking to run a professional organization that put forward high quality innovation. With such professional management, the company admitted that it has adapted many working systems of professional organizations and new technologies that can support the company's sustainability in the future.

How the market knowledge that will determine the product innovation produced by the company can be explained through several dimensions of absorption capacity as follows.

Acquisitions. Before deciding the jewelry design for the production focus, the company identified the consumer preference as explored from market survey. With the rapid development of technology, the company analyzed the consumer behaviors where accessability to information is widespread; not only coming from consumer based design, but also arising from complex issues that affect the motivation of consumers to buy. Therefore, to create product innovation, companies need to study the external value elements of a new idea, so that the product of the innovation can be a trend leader.

Based on the various informations that have been reviewed in this acquisition phase, it will be further preceded by the $\mathrm{R} \& \mathrm{D}$ unit. This unit needed to be supported by market survey for providing evidences before it is produced in large scale. The typical manufacturing condition of the jewelry company lies in the high value of the raw material, so the possibility of a defect should be avoided (to a minimum). To make a piece of jewelry is a simple thing, but if the company will do mass production process for 300 jewelry then the production process will be very different. This also applies to the marketing process, where on a small scale the company does not experience any obstacles but for large scale requires separate consideration because it involves the transfer of process from research to industry.

The R \& D team consists of 6 people, with two functional groups: drawing team and team translating the image. Since this company started from a home industry company with a non-designer background, the company's consulting experts provided training from different ways of thinking, how to work better, how to understand research and ideas diverse and understanding "meanings" (meaning an idea).

The internalization process of this new understanding was given intensively by the experts because to produce a new design was a new challenge for organizational change. Moreover, a fundamental understanding of the mindset for professional management of the company was also directed by the expert, in addition to efforts to build corporate image from core company to core design.

At the beginning of this transition process, the company has to create a window of opportunity in managing product, including how to sell the product. Since the product of jewelry is unique and very specific, a new concept and innovative idea are the key in developing product innovation. For the purpose, one of innovative organizational change has been actualized through presentation media for conducting sales in various concepts. This is to provide a better understanding of sales which previously have traditional ways of thinking, especially in convincing consumers as to why their products are better than other jewelry products, both in terms of design and in terms of image. With this transition process, the company capable to build a new image as a leading jewelry company in Indonesia. Therefore, company B is committed not to imitate competitors' products and prioritize differentiation strategies for innovation.

After the new design of the R \& D team built, it will be preceded to a more technical production process. In this case, the control of the production process is led by the expert to monitor whether the product with the design drawings is appropriate or not. If the production process has any trouble, the company will look for solutions to find ways to achieve the most efficient new targets. In addition, how to manufacture it if there is a design change so as not to change the intensity. This is because the manufacturing process in the production process of jewelry products is very different from the process of making craft products (craft), so that required a process called rough manufacturing. The process of change may be an adaptation of a new technology, or process change so that its design should be changed even if it is only $1 \%$.

For the company purpose, $\mathrm{R} \& \mathrm{D}$ division was responsible to not only creating new concepts of design, but also have to manage how to produce the products with the most efficient methods and what technology is appropriate. To achieve the cost feasibility, the production department also makes changes or modifications to the existing machinaries to expand its work function. Instead of limited information, the company operates the machine and tries to cope how it works and handles including maintainance in case of damage. In order to find a solution to the problem of appropriate technology requirements for a new design production process, the $\mathrm{R}$ \& D team conducted experiments with some trials or 
changed some sections to find a solution. Some of the findings from solution-solving problems related to production machinery become company secret.

\section{Discussions}

The identification of absorptive capacity in low tech firms shows that the source of information is largely dependent on market demands and these preferences are influenced by the external or environmental conditions of the consumer. To support the company's longterm competitiveness, sustainable capabilities are required in absorbing diverse information. If the company relies on only one source of information, it will be difficult to compete with other companies. In addition, most of technological capabilitiesdepend on technology importsfrom advanced countries also make theirproducts less competitive in the market.

It has been widely recognized that open innovation improves innovation performance. In fact, not every firm benefits equally from tapping into external knowledge in the innovation process. Open innovation contributes to competitive advantage in product innovation and now arguably this might be even more difficult to achieve given that externally access knowledge is typically also available to competitors.

Most scholars shedlight some statement by providing insights into organizational processes that help to explain into firm differences in benefiting from open innovation. This paper provides some empirical evidences that absorptive capacityin low tech sectors can indeed contribute to competitive advantage and product innovation. Some companies have created a way forward by engaging with external partners as a form of open innovation.

As a lesson learned that will become evidence for policy recommendation, the question of open innovation effectiveness is crucial. This is because knowledge and competencies related to product innovation that we are traditionally developed internally are now increasingly accessed from a broad set of external parties and so given this investment in external knowledge sourcing. It is essential to understand whether it actually contributes a competitive advantage so does open innovation lead to higher product effectiveness and higher product efficiency compared to other competitors and to answer this absorptive capacity as a theoretical lens. Both open innovation and absorptive capacity focus on how innovating firms can effectively use external knowledge.

As discussed in the previous section, absorptive capacity consists of three components the capacities to recognize, assimilate, and capacities to recognize, assimilate and exploit external knowledge. These abstract components are embedded in organizational processes, therefore, for example, assimilation capacity should be captured in terms of coordination, integration and knowledge management processes. The underlying measurement items provide concrete organizational activities and systems. In this case, it is important for a company to have a reward and incentive system for actually utilizing external knowledge. Another significant point that should be addressed is the availability of a system for searching, analyzing and filtrating external knowledge, that can generate a company likely to have a higher level of simulation capacity. These components capacity are associated with external technological resource access that is a measure of open innovation and are associated with competitive advantage and product innovation.

\section{Conclusions}

This paper attempts to analyze how company in low tech sectors in Indonesia gained their industrial competitiveness by indicating their absorptive capacity from external source of knowledge. Most of the firms are rarely conducted $R \& D$ activities, but the activities of research embedded in the production system, and marketing research. For enhancing the technological capabilities, most of the firms experienced some training from the suppliers through technology acquisition and licensing system. These activities are supporting factors for acquiring new technological changes to produce new products and services. It reflected that innovation capabilities of low tech industries in Indonesia are mainly driven by market demand. Therefore, in term of technological capabilities, they still depend on technology import from advanced countries.

In the long term, this dependency will create a lag behind and a new trap for domestic firms to be competitive in global market. Regarding the relationship between potential absorptive capacity and realized absorptive capacity, low tech industries are characterized by process, organizational and marketing innovations, by weak internal innovation capabilities (even to the extent that most lack of R\&D facilities) and by strong dependencies on the external provision of inputs, i.e. suppliers

This paper has important implications for policy makers especially in generating innovating process of non $\mathrm{R} \& \mathrm{D}$ performers which are mainly dominant in low tech sectors. Innovation in product needs $R \& D$ activities and university supports, while innovation in process requires a different input of innovation activities. However, for low tech sectors these kinds of resources can be achieved with the idea of open innovation to reinforce firm's internal resources and external knowledge. Therefore, policy makers should pay attention to the fact that innovative performance can be achieved without R\& activities, but open innovation will disclose a wide opportunities to access new ideas with cooperation agreements.

\section{Acknowledgements}

This paper is partly a result of research activities conducted in 2013, funded by Research Center for Science and Technology Devlopment, Indonesian Institute of Sciences (PAPPIPTEK-LIPI). The authors 
would like to thank the team in this research for giving supports and comments.

\section{References}

[1] Asmara, I.J., Berliana, N.G., Ariana, L., Rahmaida, R., Kusnandar. (2013) 'Studi Analisis Kapasitas Absorpsi pada Industri manufaktur teknologi rendah'. Serial report series of Research Center for Science and Technology Development, Indonesian Institute of Sciences, Jakarta

[2] Camisón C., Forés B. (2010) 'Knowledge absorptive capacity: New insights for its conceptualization and measurement'. Journal of Business Research 63, 707-715.

[3] Cohen, W., Levinthal, D. (1990) 'Absorptive capacity: a new perspective on learning and innovation'. Administrative Science Quarterly, $35,128-152$

[4] Hirsch-Kreinsen, H. (2008) 'Low -technology: a forgotten sector in innovation policy.' Journal of Technology Management \& Innovation, 3, 11-20

[5] (2011) 'Innovation Survey' Serial Research Report. Research Center for Science and Technology Development, Indonesian Institute of Sciences (LIPI), Jakarta.

[6] Jensen, M.B., Johnson, B., Lorenz, E., Lundvall, B.A. (2007) 'Forms of knowledge and modes of innovation'. Research Policy, 36 (5), 680-693

[7] Katila, R., Ahuja, G. (2002) 'Something old, something new: a longitudinal study of search behavior and new product introduction'. Academy of Management Journal, 45 (6), 1183-1194

[8] Katz, J. Corbett, A. C. (1995) 'Advances in Entrepreneurship, Firm Emergence and Growth.' Emerald Group.

[9] Kirner, E., Kinkel, S., Jaeger, A. (2009) 'Innovation paths and the innovation performance of low-technology-firms - an empirical analysis of German industry.' Research Policy, 38, 447-458

[10] Liao, J. W., Welsch, H., \& Stoica, M. (2003) 'Organisational absorptive capacity and responsiveness: an empirical investigation of growth-oriented SMEs.' Entrepreneurship Theory and Practice, 28(1), 63-85

[11] Lane, P., Koka, P., Pathak, S. (2006) 'The reification of absorptive capacity: a critical review and rejuvenation of the construct.' Academy of Management Review, 31 (4), 833863

[12] Piva, C., Vivarelli, M., (2005) 'Innovation and employment: evidence from Italian microdata.' J. Econ. 86, 65-83.
[13] Robertson, P., Pol, E., Carroll, P., (2003) 'Receptive capacity of established industries as a limiting factor in the economy's rate of innovation'. In: Paper presented at the PILOT Workshop on Concepts, Theory, Taxonomies and Data. Department of Industrial Economics and Management, Royal Institute of Technology in Stockholm, 26-27 September 2003

[14] Zahra, S.A. George, G. (2002) 'Absorptive capacity: a review, reconceptualization, and extension.' Academy of Management Review, $27,185-203$ 